\title{
Magnolol exerts anti-asthmatic effects by regulating Janus kinase-signal transduction and activation of transcription and Notch signaling pathways and modulating Th1/Th2/Th17 cytokines in ovalbumin-sensitized asthmatic mice
}

\author{
Qi Huang, Lele Han, Rong Lv, and Ling Ling* \\ Department of Gerontology, Wujiang Hospital Affiliated to Nantong University, Suzhou, Jiangsu 215505, China
}

\author{
ARTICLE INFO \\ Received November 12, 2018 \\ Revised January 9, 2019 \\ Accepted January 10, 2019 \\ *Correspondence \\ Ling Ling \\ E-mail: ISwoggerisits@yahoo.com
}

\section{Key Words}

Asthma

Cytokines

JAK-STAT pathway

Magnolol
ABSTRACT Allergic asthma, is a common chronic inflammatory disease of the airway presenting with airway hyperresponsiveness and airway remodelling. T helper cellsderived cytokines are critically associated with asthma pathogenesis. Janus kinasesignal transduction and activation of transcription (JAK/STAT) signaling is found to be involved in asthma. Magnolol is a plant-derived bioactive compound with several pharmacological effects. The study aimed to assess the effects of magnolol in ovalbumin (OVA)-induced asthmatic model. BALB/c mice were sensitized and challenged with OVA. Magnolol $(12.5,25$, or $50 \mathrm{mg} / \mathrm{kg}$ body weight) was administered to separate groups of animals. Dexamethasone was used as the positive control. Cellular infiltration into the bronchoalveolar lavage fluid (BALF) were reduced on magnolol treatment. The levels of Th2 and Th17 cytokines were reduced with noticeably raised levels of interferon gamma. Lung function was improved effectively along with restoration of bronchial tissue architecture. OVA-specific immunoglobulin E levels in serum and BALF were decreased by magnolol. Magnolol reduced Th17 cell population and effectively modulated the JAK-STAT and Notch 1 signaling. The results suggest the promising use of magnolol in therapy for allergic asthma.

\section{INTRODUCTION}

Allergic diseases including food allergies, conjunctivitis, allergic asthma and rhinitis, are on a rise worldwide, affecting approximately 1 out of 5 people [1]. Bronchial asthma is a common allergic disease with hallmark symptoms including inflammation of the airways, airway hyperresponsiveness (AHR), cough, dyspnoea, wheezing mucus hypersecretion, and airway remodelling $[2,3]$. The T helper 2 (Th2) cells are crucially involved in allergic asthma. Th2 cells produce cytokines-interleukin (IL) 4, IL-5, and IL-13 that are majorly responsible for inflammation in asth$\mathrm{ma}[4,5]$. IL-4 and -13 induce the production of immunoglobulin E (IgE) while IL-5 exerts vital roles in differentiation and activa- tion of eosinophils [6,7]. Immune responses exerted by Th2 cells is balanced by Th 1 cells that secrete interferon (IFN) $-\gamma$. IL- 4 is involved in class switching of IgG1 and in synthesis of IgE, while, IFN- $\gamma$ is implicated in the class switching of IgG2 $\alpha$ levels of allergen specific IgE and Th1/Th2 cytokine balance is vital in asthma assessment [8]. Th17 cells, another subset of Thelper cell secretes several cytokines, including IL-17, IL-6, IL-22, and TNF- $\alpha[9,10]$. IL-17 is associated with recruitment for airway macrophages [11].

Janus kinase-signal transduction and activation of transcription (JAK/STAT) pathway, a major cell signaling cascade, is well documented in Th2 cell differentiation [12] and in Th17 cell differentiation, survival and proliferation [13]. JAKs are regulators of signaling via the cytokine receptors. JAK1 and JAK3 play crucial
(1) \$ This is an Open Access article distributed under the terms of the Creative Commons Attribution Non-Commercial License, which permits unrestricted non-commercial use, distribution, and reproduction in any medium, provided the original work is properly cited. Copyright @ Korean J Physiol Pharmacol, pISSN 1226-4512, elSSN 2093-3827
Author contributions: Q.H. and L.L. designed the study. Q.H., L.H., R.L., and L.L. performed experiments and analysed the data and prepared this manuscript. All authors had equally contributed to this work and performed all activities relating to this study. 
roles in the initiation of inflammatory responses [14]. Studies have reported that the JAK-STAT pathway in asthma [15] and in allergic rhinitis [16]. It is known that allergic diseases are predominantly characterized by elevated levels of IL-4, IL-5, IL-13 and IL-31. Further, binding of these cytokines with their respective receptors activate the JAK/STAT signaling [17].

Further, Notch signaling pathway is also reported to be involved in pathogenesis of asthma [18]. Notch1 is found to play a distinct role in $\mathrm{T}$ cell development and in Th1/Th2 imbalance in asthma $[18,19]$. Studies have shown increased protein levels of Notch1 in ovalbumin (OVA)-sensitized mice [20,21]. Also, inhibition of Notch1 signaling by $\gamma$-secretase inhibitor was found to cause a decrease in Th2 cytokine production while it raised Th1 cytokine levels, thus aiding in alleviation of asthma-induced pathological changes [20].

In recent years, a number of plant-derived compounds have been found to regulate JAK/STAT pathway and inflammatory responses [3,22,23]. Magnolol, a neolignan isolated from Magnolia officinalis, is found to exert a broad spectrum of pharmacological effects including anticancer [24,25], antioxidant and anti-inflammatory activities $[26,27]$. The present study we explored the effects of magnolol on inflammatory responses and on JAK/STAT and Notch signaling in OVA-sensitized mice model of asthma.

\section{METHODS}

\section{Chemicals and antibodies}

Antibodies against JAK1, JAK2, JAK3, STAT1, STAT3, STAT6, p-STAT1, p-STAT3, p-STAT6, $\beta$-actin (Cell Signaling Technology, Beverly, MA, USA), Jagged1, Jagged2 and Notch1 (Santa Cruz Biotechnology, Santa Cruz, CA, USA) were used for expression analysis. OVA, magnolol, methacholine and other chemicals and reagents used were got from Sigma-Aldrich (St. Louis, MO, USA) otherwise are specified.

\section{Animals and study design}

Female BALB/c mice ( $\mathrm{n}=90 ; 25-38 \mathrm{~g}$ ) obtained from the University Centre of small animal breeding. The mice were placed in sterile cages under regulated conditions of temperature $\left(22^{\circ} \mathrm{C}\right.$ $\left.\pm 3^{\circ} \mathrm{C}\right)$, humidity $(55 \% \pm 5 \%)$ and $12 \mathrm{~h} / 12 \mathrm{~h}$ day/night cycle. The mice were given free provided with adequate food and drinking water through the entire period of study. Study design and protocols were approved by the Ethical Committee of the Institute (approval number: TXY2015831). The animals were handled and housed as per the guidelines of National Animal Welfare Law of China and in compliance with the US National Institutes of Health Guidelines for the Care and Use of Laboratory Animals [28].

The mice were acclimatized to in-house conditions for 7 days prior induction of asthma. The mice were subjected to allergic asthma by OVA sensitization and inhalation as described Oh et al. [29] with slight modifications. In phosphate-buffered saline (PBS), $500 \mu \mathrm{g} / \mathrm{ml}$ of OVA was mixed with equal volumes of $10 \%$ (w/v) of aqueous alum. The $\mathrm{pH}$ was adjusted to 6.5 and the mixture was incubated for $1 \mathrm{~h}$ at room temperature. Following incubation, the mixture was centrifuged at $750 \mathrm{~g}$ for $5 \mathrm{~min}$. The OVA/alum pellet was resuspended in distilled water to its original volume. On day 1 , the animals were administered OVA at $100 \mu \mathrm{g}(0.2 \mathrm{ml}$ of $500 \mu \mathrm{g} /$ $\mathrm{ml}$ OVA in normal saline) intraperitoneally (i.p.). The mice were then exposed to $250 \mu \mathrm{g}$ OVA on day 8 (100 $\mu \mathrm{l} ; 2.5 \mathrm{mg} \mathrm{OVA} / \mathrm{ml})$. On days 15,18 , and 21 , the animals were challenged with OVA at $125 \mu \mathrm{g}$ ( $50 \mu \mathrm{l}$ of $2.5 \mathrm{mg} / \mathrm{ml}$ solution) intranasally as described by Oh et al. [29]. Mice were exposed to ketamine-xylazine anesthesia via i.p. $(0.2 \mathrm{ml}$ ketamine at $0.44 \mathrm{mg} / \mathrm{ml}$ and xylazine at $6.3 \mathrm{mg} /$ $\mathrm{ml}$ in normal saline prior OVA challenge). Magnolol at 12.5, 25, $50 \mathrm{mg} / \mathrm{kg}$ body weight was administered to treatment group mice everyday via oral gavage, starting from 1st day of OVA exposure to day 21 . On the days of OVA challenge magnolol was administered $60 \mathrm{~min}$ prior before each injection. Mice that received dexamethasone (Dex) at $2 \mathrm{mg} / \mathrm{kg}$ dose via i.p. an hour prior every OVA injection served as positive control. The control mice were not challenged with OVA and they received equal volumes of normal saline for magnolol.

\section{Collection and analysis of bronchoalveolar lavage fluid (BALF)}

Twenty-four hours following the last OVA challenge, the mice were sacrificed by pentobarbital overdose ( $50 \mathrm{mg} / \mathrm{kg}$ body weight) and tracheotomy was done. Ice-cold PBS $(0.5 \mathrm{ml})$ was infused into a lung and BALF was collected via tracheal cannulation. BALF was collected by three successive aspirations (total volume $1.5 \mathrm{ml}$ ) [30] and then centrifuged $\left(4^{\circ} \mathrm{C}, 250 \mathrm{~g}\right)$ for $5 \mathrm{~min}$. The supernatant collected was stored $\left(-70^{\circ} \mathrm{C}\right)$ until use. The supernatant was used for assessment of cytokines.

Cytokines IL-4, IL-5, IL-6, IL-13, IL-17A and IFN- $\gamma$ in the BALF were determined by ELISA. The kits for analysis of IL-6, IL-17A and IFN- $\gamma$ were purchased from R\&D Systems (Minneapolis, MN, USA). ELISA kits for IL-4, IL-5 and IL-13 were purchased from Biolegend (San Diego, CA, USA). The analysis was performed as per manufacturer's protocol. Further, for determination of differential cell counts, cell pellets were re-suspended in PBS and stained with Wright-Giemsa stain (Nanjing Jiancheng Bioengineering Institute, Nanjing, China).

\section{Determination of OVA-specific IgE in serum and BALF}

The serum separated from whole blood by centrifugation (10 $\min ; 3,000$ revolutions per $\min ; 4^{\circ} \mathrm{C}$ ) was used for determination of OVA-specific IgE by ELSIA using LEGEND MAX ${ }^{\mathrm{TM}}$ Mouse OVA specific IgE kit (BioLegend) as per manufacturer's instruc- 
tions.

\section{Flow cytometric analysis of Th17cells}

Th17 cell population was determined by flow cytometric analysis. Spleen excised from the mice of different experimental groups was placed in RPMI1640 media (Gibco, Grand Island, NY, USA). The spleen was disrupted using a cell disrupter (Beckman, Brea, CA, USA) to prepare a single cell suspension. The cells were washed in PBS. The cell pellet separated from BALF was resuspended in FBS and the supernatant was discarded. The cell pellet prepared from BALF and the cells of the spleen were incubated for $30 \mathrm{~min}$ with fluorescein isothiocyanate antihuman CD4 (eBioscience Co., San Diego, CA, USA) at $4^{\circ} \mathrm{C}$. The cells were then fixed and permeabilized as per manufacturer's protocol, and were then stained with phycoerythrin anti-mice IL-17A (eBioscience Co). The cells were analyzed for Th17 cell population by flow cytometry (FACS, Calibur instrument with CellQuest software; BD Biosciences, Mountain View, CA, USA).

\section{Determination of airway hyperresponsiveness}

Functional changes of the airway following OVA challenge was assessed using methacholine. AHR to aerosolized methacholine was assessed within $24 \mathrm{~h}$ following final exposure to OVA. Buxco's modular and invasive system (Buxco Electronics Inc., Wilmington, NY, USA) was used to determine changes in lung dynamic complianc (Cdyn) and airway resistance (RI). Cdyn and $\mathrm{RI}$ in response to increasing concentrations of methacholine were recorded as described by Pichavant et al. [31]. In brief, the mice were tracheostomized and cannulated and laid in a whole-body plethysmograph chamber that was connected to the ventilator. The mice were administered methacholine at $3.125,6.25,12.5$, or $25 \mathrm{mg} / \mathrm{ml}$ via a jet nebulizer into the head chamber. The values are expressed as percentage of the respective basal values as described by Glaab et al. [32].

\section{Histologic analysis}

Following collection of BALF, lungs were excised and fixed in $10 \%$ formalin, paraffinized and uniform sections $(5 \mu \mathrm{m})$ were cut and stained with hematoxylin and eosin (H\&E) to examine cellular infiltration into the peribronchial connective tissues. Cell count based on a five-point scoring system was done as described by Duan et al. [33]. The cell counts were scored as: 0 , no cells; 1 , a few cells; 2 , a ring of cells 1 cell layer deep; 3 , a ring of cells 2 to 4 cell layers deep; and 4 , a ring of cells more than 4 cell layers deep.

\section{Western blotting}

The lung tissues were homogenized in liquid nitrogen and incubated in cell lysis buffer containing protease and phosphatase inhibitors (Roche, Basel, Switzerland) to obtain protein extracts. The total protein content present was determined using protein assay kit (Bio-Rad Laboratories, Hercules, CA, USA). Equal concentration of the protein samples $(50 \mu \mathrm{g})$ were loaded on to $10 \%$ to $12 \%$ sodium dodecyl sulphate-polyacrylamide gel electrophoresis (SDS-PAGE) gels and subjected to electrophoresis. The bands obtained were transferred onto a polyvinylidene difluoride membrane (Millipore, Temecula, USA). The membranes were then blocked with $5 \%$ non-fat dry milk and incubated with primary antibodies overnight at $4^{\circ} \mathrm{C}$. The membranes were further incubated with peroxidase-conjugated secondary antibodies at room temperature for $1 \mathrm{~h}$. The immunoreactive bands were visualized and analysed using a chemiluminescence system (Amersham Bioscience, Buchinghamshire, UK). The band intensities were normalized to $\beta$-actin expression that was used as internal control.

\section{Statistical analysis}

The values are expressed as the mean \pm standard deviation; $\mathrm{n}$ $=6$. The results were analyzed by one-way analysis of variance (ANOVA) and Duncan's multiple range test (DMRT) using SPSS version 22.0 (IBM Co., Armonk, NY, USA); a p-values $<0.05$ were considered significant.

\section{RESULTS}

\section{Magnolol reduces airway hyperresponsiveness}

Asthma is characterized by non-specific hyperresponsiveness of the airway in response to various allergens and contractile agonists as OVA. In the study, effects of magnolol $(12.5,25$, and $50 \mathrm{mg}$ ) on AHR was determined by measuring Cdyn and RI in response to increasing doses of methacholine in mechanically ventilated mice. RI is defined as the pressure driving respiration by air flow. Lung compliance is the distensibility of the lungs and is defined as the change in lung volume due to change in lung pressure. Here, OVA sensitization and challenge induced AHR, as reflected by significantly $(\mathrm{p}<0.05)$ high RI and low Cdyn (Fig. 1) v.s. control mice not exposed to OVA. Interestingly, magnolol administration at the tested doses significantly $(\mathrm{p}<0.05)$ reduced $\mathrm{RI}$ and restored Cdyn in response to methacholine. Also, magnolol at $50 \mathrm{mg}$ exhibited maximum protective effects as against lower doses more positive results and the effects were close to that of positive control, Dex.

\section{Magnolol inhibited inflammatory cell infiltration into BALF}

Inflammatory responses are well established in allergic conditions as asthma. The effects of magnolol on cellular infiltration 
A

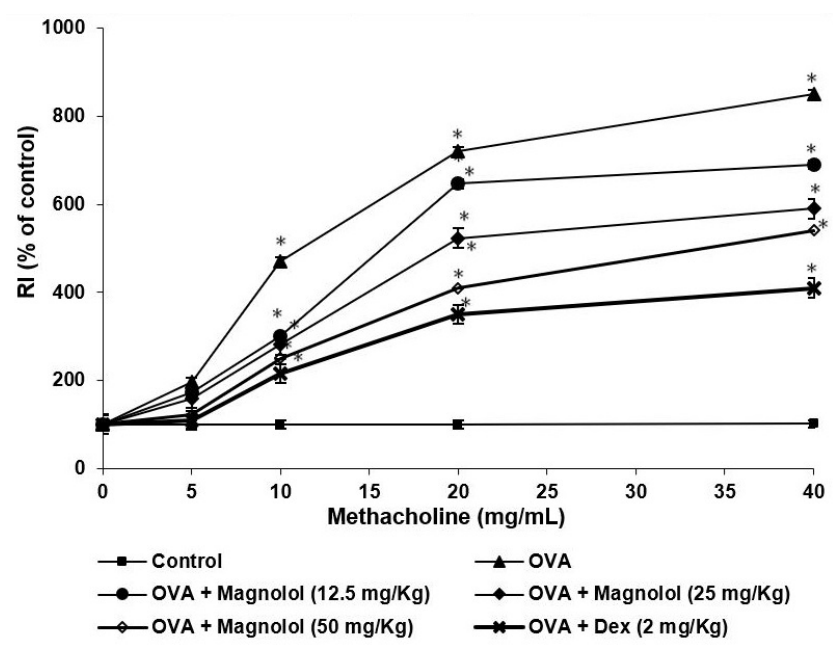

B

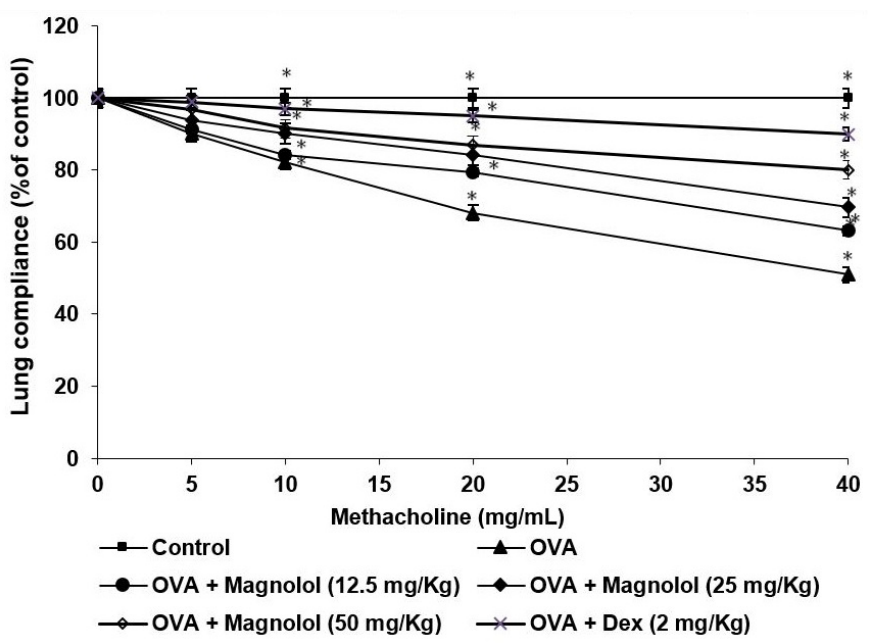

Fig. 1. Effect of magnolol on lung function. (A) Airway resistance and (B) lung compliance of mice exposed to ovalbumin (OVA). Values are represented as mean \pm standard deviation; $n=6 .{ }^{*} p<0.05$ v.s. control as determined by one way-ANOVA followed by Duncan's multiple range test analysis. Dex, dexamethasone.

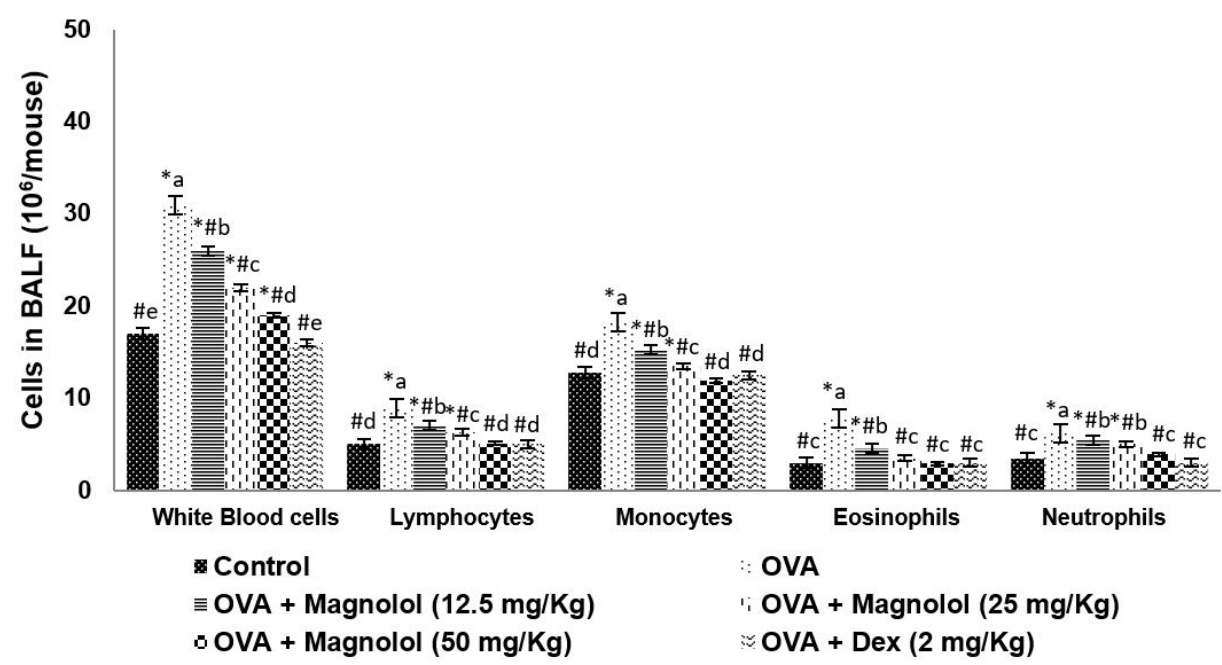

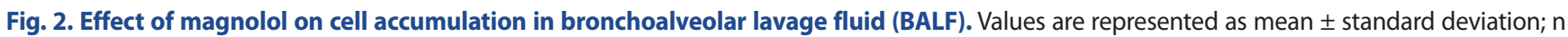
$=6 .{ }^{*} p<0.05$ compared against control; ${ }^{*} p<0.05$ compared against ovalbumin (OVA) alone group; ${ }^{\text {a-e }}$ Significant difference $(p<0.05)$ between mean values within the groups as determined by one-way ANOVA followed by Duncan's multiple range test analysis. Dex, dexamethasone.

into the BALF were determined. OVA-sensitized mice, exhibited severe infiltration of eosinophils and leukocytes in the BALF (Fig. 2). Magnolol supplementation significantly $(\mathrm{p}<0.05)$ inhibited cellular infiltration following OVA sensitization and challenge as reflected by the decrease in number of eosinophils, macrophages and neutrophils in the BALF. Further 50-mg magnolol exhibited suppressive effects in line with standard drug, Dex.

\section{Magnolol reduced levels of OVA specific lgE}

Raised expressions of allergen-specific IgE on the surface of mast cells in response to an allergen challenge is regarded as one of the early events in asthma. OVA-specific IgE levels in the serum and BALF was determined $24 \mathrm{~h}$ following the last OVA challenge. OVA exposure caused a significant increase $(\mathrm{p}<0.05)$ in the serum and BALF levels of OVA-specific IgE v.s. control mice. Interestingly, magnolol treatment to OVA-sensitized animals significantly $(p<0.05)$ reduced the levels of OVA-specific IgE in both serum and in BALF (Fig. 3). Magnolol of $50 \mathrm{mg}$ reduced the levels to almost 5 times in serum and 4 times in BALF. 


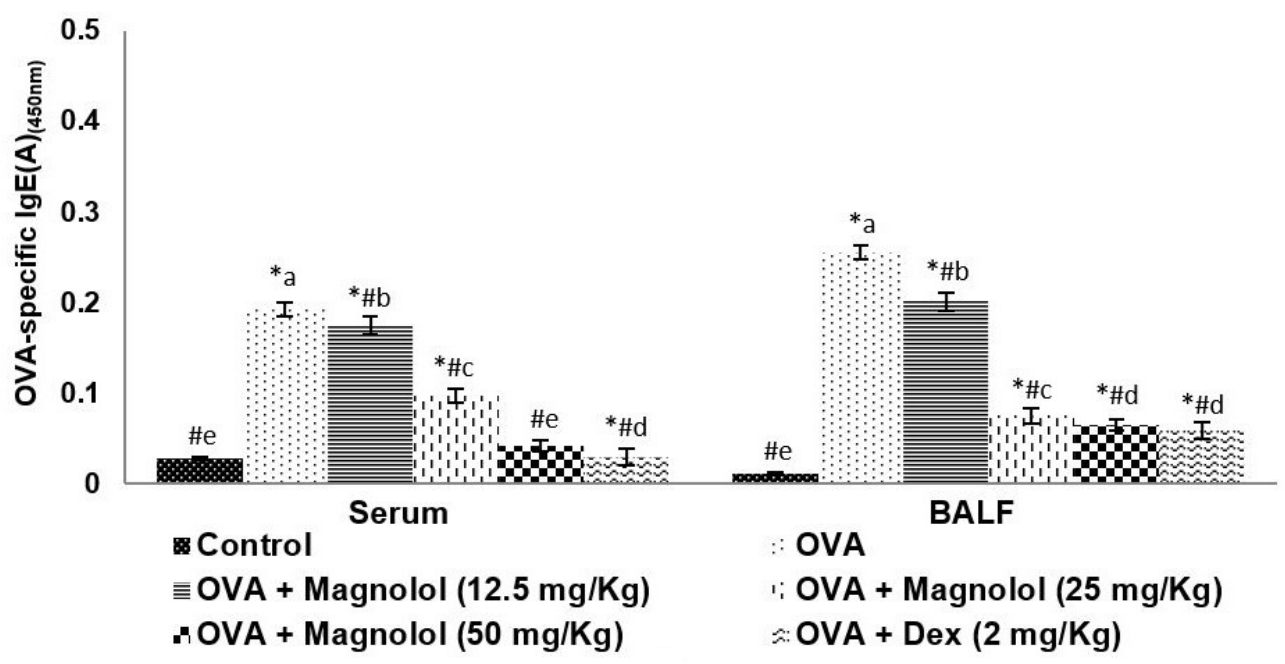

Fig. 3. Magnolol reduced levels of ovalbumin (OVA)-specific immunoglobulin E (IgE). Values are represented as mean \pm standard deviation; $\mathrm{n}=$ 6. ${ }^{*} p<0.05$ compared against control; ${ }^{*} p<0.05$ compared against OVA alone group; ${ }^{\text {a-e }}$ Significant difference $(p<0.05)$ between mean values within the groups as determined by one-way ANOVA followed by Duncan's multiple range test analysis. BALF, bronchoalveolar lavage fluid; Dex, dexamethasone.

A

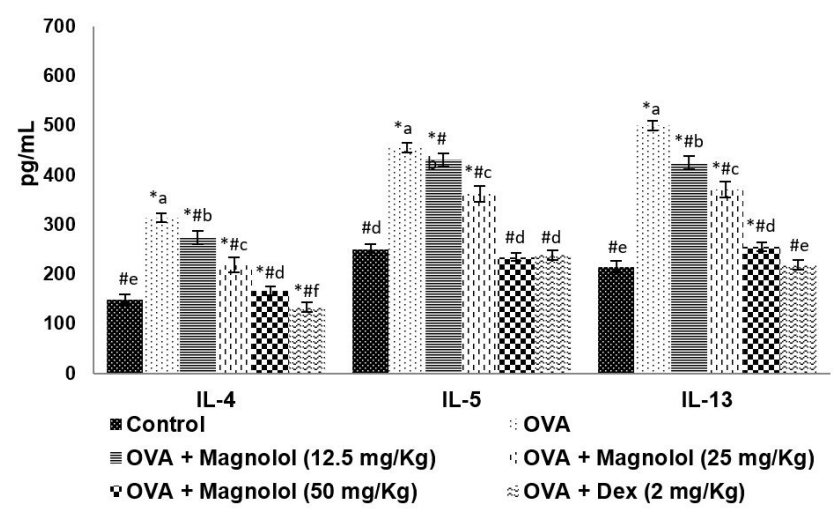

B

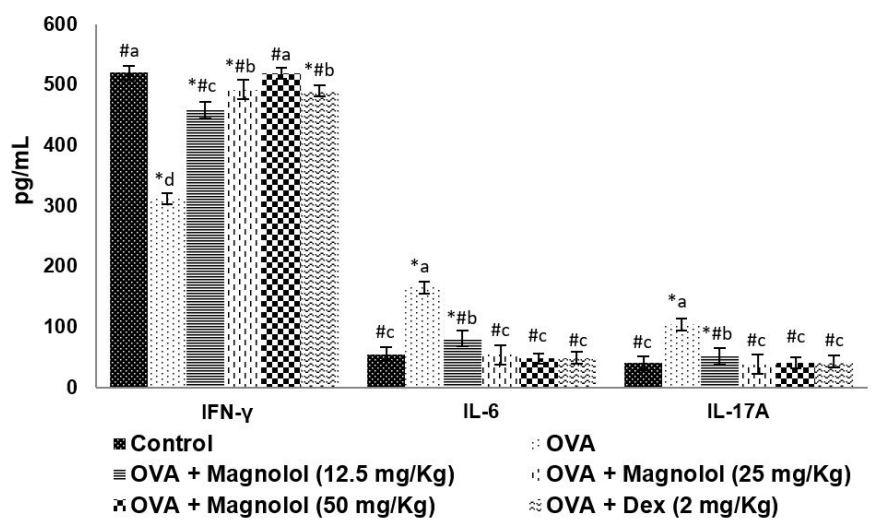

Fig. 4. Effect of magnolol on cytokines. Values are represented as mean \pm standard deviation; $n=6$. ${ }^{*} p<0.05$ compared against control; ${ }^{\#} p<0.05$ compared against ovalbumin (OVA) alone group; ${ }^{\text {ae }}$ Significant difference $(p<0.05)$ between mean values within the groups as determined by oneway ANOVA followed by Duncan's multiple range test analysis. IL, interleukin; Dex, dexamethasone.

\section{Magnolol restores Th1/Th2 cytokine balance and regulates Th17 cytokine levels}

Th1/Th2/Th17 cytokines play vital roles in allergic asthma. The effects of magnolol the cytokine levels in the BALF were determined. Th2 cytokines (IL-4, IL-5, and IL-13) and Th17 cytokines-IL-17A and IL- 6 were observed to be significantly raised $(\mathrm{p}<0.05)$ following OVA sensitization and challenge (Fig. 4A, B). However, IFN- $\gamma$, the Th1 cytokine $(\mathrm{p}<0.05)$ was markedly decreased. Magnolol caused a significant $(p<0.05)$ decrease in the levels of Th2 and Th17 cytokines along with a noticeable increase in IFN- $\gamma$ in a dose-dependent manner. A 50-mg dose of magnolol decreased IL-17A and IL-6 from 104 and $165 \mathrm{pg} / \mathrm{ml}$ to 41 and 48 $\mathrm{pg} / \mathrm{ml}$, respectively; while IFN- $\gamma$ levels increased from 312 to 519 $\mathrm{pg} / \mathrm{ml}$. The observations indicate the effective restoring of the Th1/Th2 balance and Th17 cytokine levels in line with the effects of Dex.

\section{The effect of magnolol on Th17 cell population}

Th17 cells are known to be involved in inflammatory responses following allergen exposure. The relative proportion of Th17 cells was determined in the spleen of mice following OVA challenge. Flow cytometry showed dramatically $(\mathrm{p}<0.05)$ increased number of Th17 cells v.s. normal control (Fig. 5). The Th17 population was found to be raised 6.5 folds as compared to control. Administration of magnolol at all the 3 tested doses significantly $(\mathrm{p}<$ $0.05)$ decreased Th17 cells. The Th17 cell population was reduced 


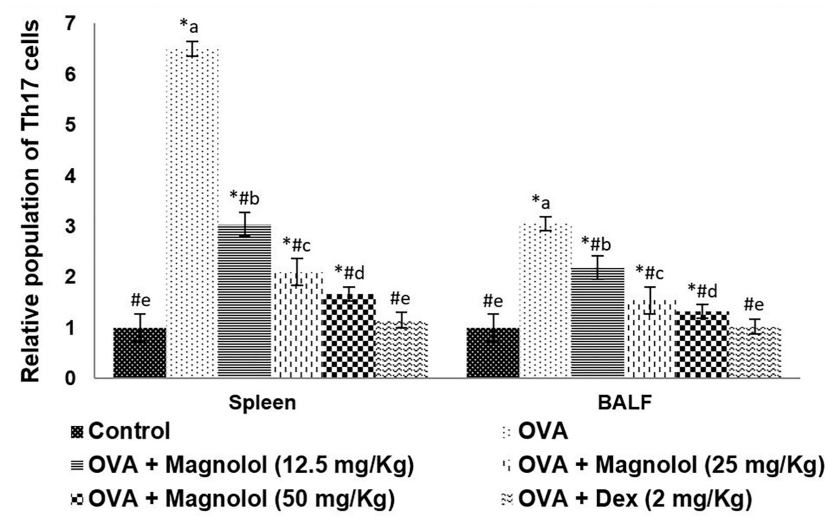

Fig. 5. Magnolol regulates T helper 17 (Th17) cell populations in bronchoalveolar lavage fluid (BALF). Values are represented as mean \pm standard deviation; $\mathrm{n}=6$. ${ }^{*} \mathrm{p}<0.05$ compared against control; ${ }^{*} \mathrm{p}<$ 0.05 compared against ovalbumin (OVA) alone group; ${ }^{\text {a-e }}$ Significant difference $(p<0.05)$ between mean values within the groups as determined by one-way ANOVA followed by Duncan's multiple range test analysis. Dex, dexamethasone.

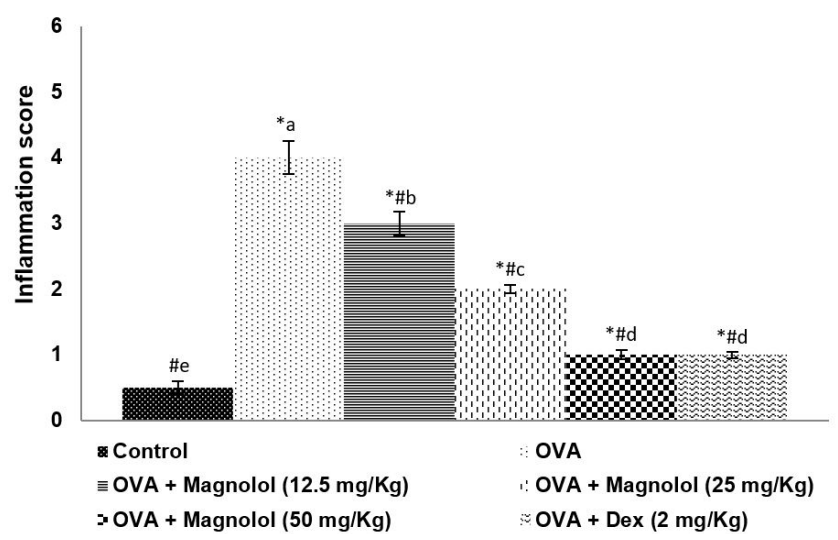

Fig. 6. Magnolol reduced inflammation score following ovalbumin (OVA) induction. Values are represented as mean \pm standard deviation; $\mathrm{n}=6 .{ }^{*} \mathrm{p}<0.05$ compared against control; ${ }^{\sharp} \mathrm{p}<0.05$ compared against OVA alone group; ${ }^{\text {aee }}$ Significant difference $(p<0.05)$ between mean values within the groups as determined by one-way ANOVA followed by Duncan's multiple range test analysis. Dex, dexamethasone.

to near normal counts with 50-mg magnolol. This reduction in Th17 cell population by magnolol could be responsible to the decreased levels of cytokines IL-6 and IL-17A.

\section{Magnolol restores lung architecture following OVA challenge}

Histological analysis of the lung tissues following OVA challenge was determined by H\&E staining. The lung tissues revealed marked infiltration of inflammatory cells into the peribronchiolar and perivascular connective tissues upon OVA-sensitization and challenge (Fig. 6). Magnolol administration was observed to markedly inhibit the infiltration inflammatory cells-eosinophils

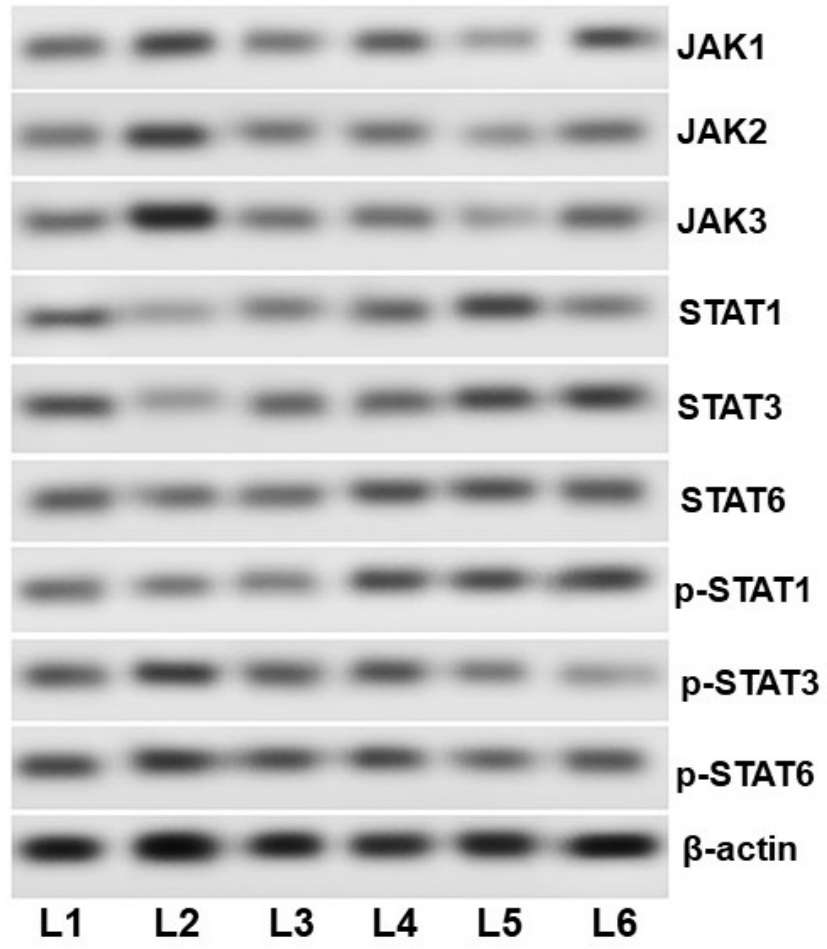

Fig. 7. Magnolol activated the Janus kinase (JAK)/signal transduction and activation of transcription (STAT) pathway following ovalbumin (OVA) challenge. L1, control; L2, OVA; L3, OVA + magnolol (12.5 $\mathrm{mg} / \mathrm{kg}) ; \mathrm{L} 4$, OVA + magnolol $(25 \mathrm{mg} / \mathrm{kg}) ; \mathrm{L} 5$, OVA + magnolol $(50 \mathrm{mg} /$ $\mathrm{kg}) ;$ L6, OVA + dexamethasone ( $2 \mathrm{mg} / \mathrm{kg})$.

and neutrophils into the lung tissues. Eosinophilia observed on OVA challenge was substantially decreased in line with cellular infiltration into BALF. Also, magnolol considerably restored lung architecture to near normal with $50 \mathrm{mg}$ dose exerting maximum protective effects. Mice treated with $50 \mathrm{mg}$ magnolol revealed nearly normal lung histology.

\section{Activation of JAK-STAT pathway following OVA- sensitization and challenge}

JAK-STAT pathway is well documented in the pathogenesis of asthma. The pathway is known to affect the Th1/Th2 differentiation and imbalance [12]. Here the effect of magnolol on the major proteins of the pathway was evaluated by western blotting. OVA challenge markedly raised the expressions of JAK1, JAK2, JAK3 and p-STAT1, p-STAT3, p-STAT6 suggesting activation of the pathway (Fig. 7). The expressions of total STAT1, STAT3, and STAT6 were also increased noticeably. However, magnolol treatment significantly down-regulated the phosphorylated levels of STAT1, STAT3, and STAT6 indicating down-regulation of the pathway. Further, the expressions of JAK1, JAK2, and JAK3 were noticed to be considerably reduced. Magnolol-mediated reduced levels of ILs could have in part aided in down-regulation of the JAK/STAT pathway. 
A

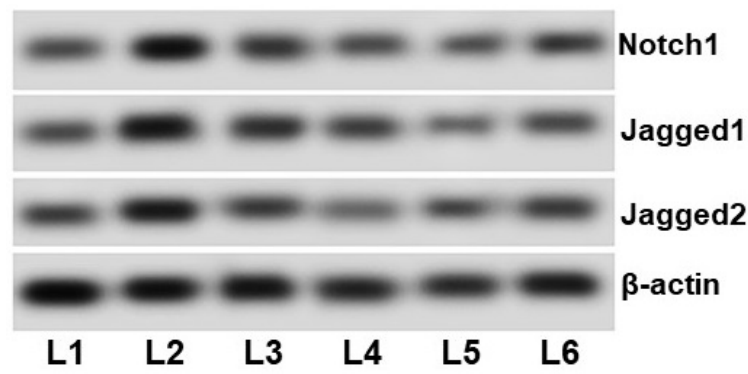

B

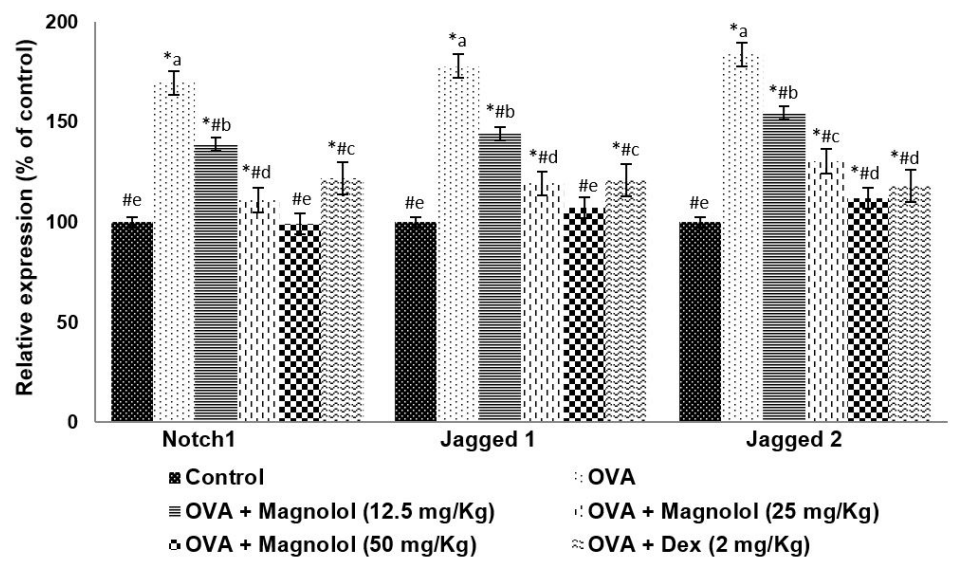

Fig. 8. Effect of magnolol on Notch signaling. (A) Representative immunoblot. (B) Relative expressions of proteins. Values are represented as mean \pm standard deviation; $n=6$. ${ }^{*} p<0.05$ compared against control; ${ }^{p} p<0.05$ compared against ovalbumin (OVA) alone group; ${ }^{\text {a-e }}$ Significant difference ( $p$ $<0.05$ ) between mean values within the groups as determined by one-way ANOVA followed by Duncan's multiple range test analysis. L1, control; L2, OVA; L3, OVA + magnolol (12.5 mg/kg); L4, OVA + magnolol (25 mg/kg); L5, OVA + magnolol ( 50 mg/kg); L6, OVA + dexamethasone (2 mg/kg).

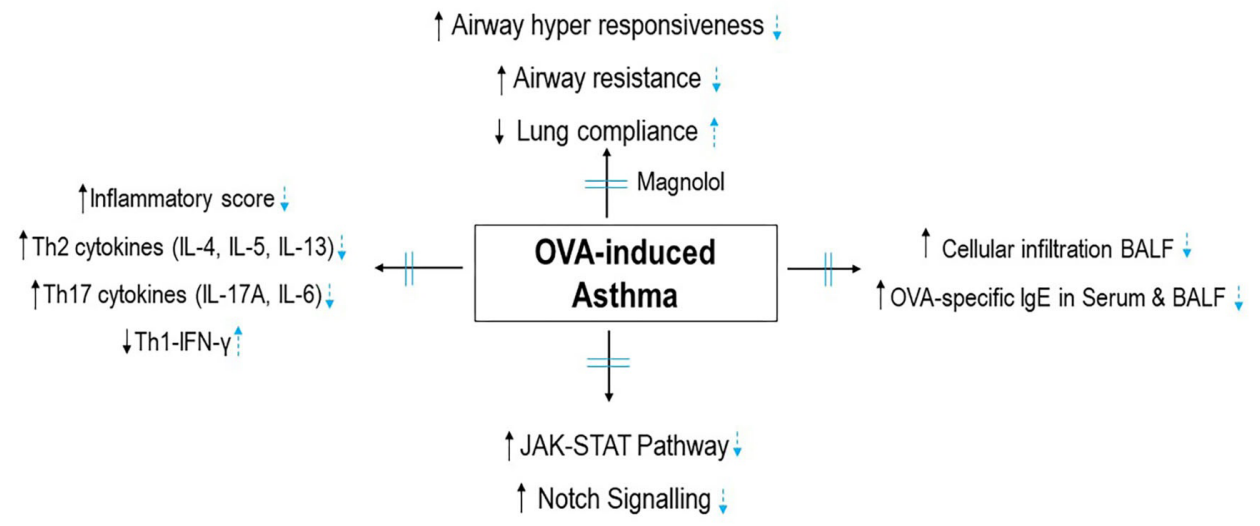

Fig. 9. Graphical representation of the protective effects exerted by magnolol. OVA, ovalbumin; Th, T helper; IL, interleukin; IFN, interferon; BALF, bronchoalveolar lavage fluid; lgE, immunoglobulin E; JAK, Janus kinase; STAT, signal transduction and activation of transcription.

\section{Magnolol modulated Notch signaling}

Notch signaling is well documented in the differentiation and activation of T cells. Here the OVA challenged mice presented with significantly $(\mathrm{p}<0.05)$ up-regulated expressions of Notch 1 receptor along with the ligands-Jagged1 and Jagged2 (Fig. 8). We observed significant $(\mathrm{p}<0.05)$ down-regulation in Notch signaling in magnolol administered mice. The expression of Notch 1 was brought to almost normal levels following administration of 50-mg magnolol. The observations reveal that effective downregulation of JAK/STAT/Notch signaling by magnolol that is suggestive of the potential anti-inflammatory effects (Fig. 9).

\section{DISCUSSION}

Asthma is a common allergic disease affecting about $7 \%$ to
$13 \%$ of the global population [34]. The pulmonary inflammatory response to allergens in asthma causes AHR, hypersecretion of mucus, bronchoconstriction and airway remodeling leading to shortness of breath, wheezing, and chest tightness [35,36]. It is a huge burden that affects the quality of living of asthma patients. Corticosteroids are currently used main therapeutic drugs for asthma [37,38]. Nevertheless, these drugs do not completely cure or modify the progression of asthma. The symptoms return once the treatment is terminated and further, continued use of these drugs may often lead to systemic and as well local side effects $[39,40]$. Thus, identification of novel effective therapeutics is of immense clinical value. In recent years the use of plant-derived compounds as alternative medicine in the treatment of various clinical conditions is increasing [41-43]. In this study, we assessed the effects of magnolol, in OVA-induced rodent model of experimental asthma.

AHR is one of the hallmark characteristics in asthma present- 
ing with bronchoconstriction due to inflammatory responses and hypertrophy of airway smooth muscles eventually resulting in impaired function of the lungs [44]. Airway functioning following OVA challenge was assessed by measuring airway RI and lung compliance. OVA exposure was found to cause increase airway RI and decreased compliance of the lungs. Magnolol improved lung function as revealed by restored lung compliance and decreasing airway RI in response to varied concentrations of methacholine.

The early responses to allergens in asthma are known to be $\mathrm{IgE}$ dependent. Higher levels of IgE has been found to be responsible for degranulation of mast cells and bronchial constriction [45]. Further, allergic airway responses in the late phase of asthma is associated with the infiltration of inflammatory cells particularly eosinophils and lymphocytes into the bronchial tissues [46,47]. Eosinophilia is a characteristic feature in asthma. The inflammatory cells produce cytokines and chemokines that induce AHR [48]. Magnolol was found to effectively attenuate the migration of inflammatory cells into the lung tissues. Magnolol strikingly reduced eosinophilia and inflammation score and as well as OVAspecific IgE levels in serum and BALF. Histological examination also revealed significantly restored lung architecture following magnolol treatment.

The crucial role of $\mathrm{T}$ lymphocytes in asthma pathogenesis is well documented, through the release of cytokines [49]. The Th2 cytokines-IL-4, IL-5, and IL-13 mediate several hallmark features including airway inflammation and AHR. Up-regulated levels of Th2 cytokines are observed in asthma [50-52]. The raised levels contribute to inflammatory cell infiltration, eosinophil activation, raised IgE production and mucus hypersecretion $[53,54]$. Cytokine, IL-4 is a key factor that is involved in isotype switching to IgE in B cells [55]. IL-5 is pivotal for eosinophil activation and survival [6] while, IL-13, is involved in eosinophil infiltration into lung tissue. IgE levels are known to dependent on IL-4 and thus the levels considered as an additional index of Th2 cytokines in asthma. Thus, IgE could be considered as a key target in developing novel anti-asthma drugs. Reducing IgE levels could be effective in asthma therapy.

Th17 cells are important subset of T-helper cells that exerts crucial roles in the pathogenesis of inflammatory diseases such as asthma $[9,10]$. Studies with rodent models of asthma have reported that Th17 cell-derived cytokines as- IL-17A and IL-17F, are implicated in recruitment and activation of antigen-induced neutrophils. Th17 cytokines were also found to enhance Th2-mediated recruitment of eosinophils into the bronchial tissues [5658]. Raised levels of Th17 cell-derived cytokines were noticed in the lung tissues and in BALF of patients with asthma and further, the levels of Th17 cytokines were reported to correlate positively with severity of AHR $[59,60]$. Thus, the increased levels of the IL$17 \mathrm{~A}$ as observed following OVA challenge indicates raised cellular infiltration and inflammation. Reduced expression of Th2 and Th17 cytokines and as well IgE levels by magnolol reveals the efficacy of magnolol in inhibiting inflammatory responses. Previ- ous studies with plant-derived compounds as curcumin exerted anti-asthmatic effects via significantly reducing cytokine levels in OVA-induced asthma [61].

Also, it is well documented that Th1 cell derived IFN- $\gamma$ suppresses Th2 cell-mediated immune responses. IFN- $\gamma$ is involved in IgG2 $\alpha$ class switching. Magnolol treatment markedly raised IFN $\gamma$ levels [8]. The raised IFN $\gamma$ levels illustrates enhanced Th1 responses that in part could have contributed to decreased $\operatorname{IgE}$ levels.

The JAK-STAT signaling pathway is well documented in Th2 differentiation predominantly and in Th1/Th2 balance [12]. JAKs belong to the family of tyrosine kinases and are regulators of signaling through cytokine receptors. Out of the 4 JAKs (JAK1, JAK2, JAK3, and TYK2) among which JAK1 and JAK3 are crucial in the initiation of inflammation [62]. Ashino et al. [12] reported that a selective inhibitor of JAK1/3 inhibited Th2 cell differentiation, down-regulated phosphorylation of STAT5 and 6, prevented AHR, mucus hypersecretion, and production of Th2 cytokine. Upon activation by phosphorylation, the active STATs translocate into the nucleus where they act as transcription factors to regulate gene expression [63-65]. STAT3 that signals downstream of IL- 6 has been found to be critical for the differentiation of Th17 cells $[66,67]$. STAT6 regulates several features of lung inflammatory responses including infiltration of inflammatory cells in to the airway, Th2 cell differentiation, and IgE production [68]. STAT1 is associated with IL6 and IL11 [14]. The observed elevated expressions of phosphorylated forms of JAK1, JA2, JAK3, STAT1, STAT3, and STAT6 reflect activation of the JAK/STAT pathway. Magnolol-mediated decrease in phosphorylated levels of JAKs and STAT1, STAT3, and STAT6 illustrates down-regulation of the pathway as a mechanism against asthma.

Notch signaling has also been reported to participate in the activation and proliferation of T cells [69-71]. In line with earlier studies raised expressions of Notch1 receptor and Jagged 1 and Jagged2 ligands following OVA challenge [42,72] were observed. Guo et al. [21] reported that blocking of Notch1 by Notch1-specific small interfering RNA, the levels of IL-4 decreased while IFN- $\gamma$ is increased, suggesting role of Notch1 signal in Th1/Th2 differentiation in asthma [21]. Magnolol effectively down-regulated the expressions of Notch1 receptor and Jagged1 and Jagged2. These observations suggest the efficacy of magnolol in regulating $\mathrm{T}$ cell differentiation and activation, thus aiding in decreased cytokine levels and inflammation.

The results indicate the efficacy of magnolol in reducing airway inflammation and AHR via JAK-STAT and Notch signaling and by regulating Th1/Th2/Th17cytokine levels. Thus, suggesting magnolol, as a potent candidate drug in asthma therapy. However, the compound has to be explored further to understand the possible mechanisms involved. 


\section{CONFLICTS OF INTEREST}

The author declares no conflicts of interest.

\section{REFERENCES}

1. Pawankar R, Canonica GW, Holgate ST, Lockey RF, Blaiss M. WAO white book on allergy [Internet]. Milwaukee: World Allergy Organization; 2013 [cited 2017 Oct 16]. Available from: http://www.worldallergy.org/UserFiles/file/ExecSummary-2013-v6-hires.pdf.

2. Galli SJ, Tsai M, Piliponsky AM. The development of allergic inflammation. Nature. 2008;454:445-454.

3. Kim MS, Cho KA, Cho YJ, Woo SY. Effects of interleukin-9 blockade on chronic airway inflammation in murine asthma models. Allergy Asthma Immunol Res. 2013;5:197-206.

4. Wegmann M. Th2 cells as targets for therapeutic intervention in allergic bronchial asthma. Expert Rev Mol Diagn. 2009;9:85-100.

5. Bosnjak B, Stelzmueller B, Erb KJ, Epstein MM. Treatment of allergic asthma: modulation of Th2 cells and their responses. Respir Res. 2011;12:114.

6. Simon D, Braathen LR, Simon HU. Eosinophils and atopic dermatitis. Allergy. 2004;59:561-570.

7. Nakajima H, Hirose K. Role of IL-23 and Th17 cells in airway inflammation in asthma. Immune Netw. 2010;10:1-4.

8. Brewer JM, Conacher M, Hunter CA, Mohrs M, Brombacher F, Alexander J. Aluminium hydroxide adjuvant initiates strong antigenspecific Th2 responses in the absence of IL-4- or IL-13-mediated signaling. J Immunol. 1999;163:6448-6454.

9. Hellings PW, Kasran A, Liu Z, Vandekerckhove P, Wuyts A, Overbergh L, Mathieu C, Ceuppens JL. Interleukin-17 orchestrates the granulocyte influx into airways after allergen inhalation in a mouse model of allergic asthma. Am J Respir Cell Mol Biol. 2003;28:42-50.

10. Schmidt-Weber CB, Akdis M, Akdis CA. TH17 cells in the big picture of immunology. J Allergy Clin Immunol. 2007;120:247-254.

11. Sergejeva S, Ivanov S, Lötvall J, Lindén A. Interleukin-17 as a recruitment and survival factor for airway macrophages in allergic airway inflammation. Am J Respir Cell Mol Biol. 2005;33:248-253.

12. Ashino S, Takeda K, Li H, Taylor V, Joetham A, Pine PR, Gelfand EW. Janus kinase $1 / 3$ signaling pathways are key initiators of $\mathrm{TH} 2$ differentiation and lung allergic responses. J Allergy Clin Immunol. 2014;133:1162-1174.

13. Li RF, Wang GF. JAK/STAT5 signaling pathway inhibitor ruxolitinib reduces airway inflammation of neutrophilic asthma in mice model. Eur Rev Med Pharmacol Sci. 2018;22:835-843.

14. Banerjee S, Biehl A, Gadina M, Hasni S, Schwartz DM. JAK-STAT signaling as a target for inflammatory and autoimmune diseases: current and future prospects. Drugs. 2017;77:521-546.

15. Hsieh YY, Chang CC, Hsu CM, Wan L, Chen SY, Lin WH, Tsai FJ. JAK-1 rs2780895 C-related genotype and allele but not JAK-1 rs10789166, rs4916008, rs2780885, rs17127114, and rs3806277 are associated with higher susceptibility to asthma. Genet Test Mol Biomarkers. 2011;15:841-847.

16. Shen Y, Liu Y, Ke X, Kang HY, Hu GH, Hong SL. Association between JAK1 gene polymorphisms and susceptibility to allergic rhinitis. Asian Pac J Allergy Immunol. 2016;34:124-129.
17. Gandhi NA, Bennett BL, Graham NM, Pirozzi G, Stahl N, Yancopoulos GD. Targeting key proximal drivers of type 2 inflammation in disease. Nat Rev Drug Discov. 2016;15:35-50.

18. Hu C, Li Z, Feng J, Tang Y, Qin L, Hu X, Zhang Y, He R. Glucocorticoids modulate Th1 and Th2 responses in asthmatic mouse models by inhibition of Notch1 signaling. Int Arch Allergy Immunol. 2018;175:44-52.

19. Amsen D, Antov A, Flavell RA. The different faces of Notch in Thelper-cell differentiation. Nat Rev Immunol. 2009;9:116-124.

20. Kang JH, Kim BS, Uhm TG, Lee SH, Lee GR, Park CS, Chung IY. Gamma-secretase inhibitor reduces allergic pulmonary inflammation by modulating Th1 and Th2 responses. Am J Respir Crit Care Med. 2009;179:875-882.

21. Guo XJ, Zhou M, Ren LP, Yang M, Huang SG, Xu WG. Small interfering RNA-mediated knockdown of Notch1 in lung. Chin Med J (Engl). 2009;122:2647-2651.

22. Vafeiadou K, Vauzour D, Lee HY, Rodriguez-Mateos A, Williams RJ, Spencer JP. The citrus flavanone naringenin inhibits inflammatory signalling in glial cells and protects against neuroinflammatory injury. Arch Biochem Biophys. 2009;484:100-109.

23. Lim H, Park H, Kim HP. Effects of flavonoids on matrix metalloproteinase-13 expression of interleukin-1 $\beta$-treated articular chondrocytes and their cellular mechanisms: inhibition of c-Fos/AP-1 and JAK/STAT signaling pathways. J Pharmacol Sci. 2011;116:221231.

24. Cheng YC, Tsao MJ, Chiu CY, Kan PC, Chen Y. Magnolol inhibits human glioblastoma cell migration by regulating $\mathrm{N}$-cadherin. $J$ Neuropathol Exp Neurol. 2018;77:426-436.

25. Ranaware AM, Banik K, Deshpande V, Padmavathi G, Roy NK, Sethi G, Fan L, Kumar AP, Kunnumakkara AB. Magnolol: a neolignan from the magnolia family for the prevention and treatment of cancer. Int J Mol Sci. 2018;19:2362.

26. Amorati R, Zotova J, Baschieri A, Valgimigli L. Antioxidant activity of magnolol and honokiol: kinetic and mechanistic investigations of their reaction with peroxyl radicals. J Org Chem. 2015;80:1065110659.

27. Huang SY, Tai SH, Chang CC, Tu YF, Chang CH, Lee EJ. Magnolol protects against ischemic-reperfusion brain damage following oxygen-glucose deprivation and transient focal cerebral ischemia. Int $J$ Mol Med. 2018;41:2252-2262.

28. National Research Council (US) Committee for the Update of the Guide for the Care and Use of Laboratory Animals. Guide for the care and use of laboratory animals. 8th ed. Washington: National Academies Press; 2011.

29. Oh SW, Pae CI, Lee DK, Jones F, Chiang GK, Kim HO, Moon SH, Cao B, Ogbu C, Jeong KW, Kozu G, Nakanishi H, Kahn M, Chi EY, Henderson WR Jr. Tryptase inhibition blocks airway inflammation in a mouse asthma model. J Immunol. 2002;168:1992-2000.

30. Djukanović R, Roche WR, Wilson JW, Beasley CR, Twentyman OP, Howarth RH, Holgate ST. Mucosal inflammation in asthma. Am Rev Respir Dis. 1990;142:434-457.

31. Pichavant M, Goya S, Hamelmann E, Gelfand EW, Umetsu DT. Animal models of airway sensitization. Curr Protoc Immunol. 2007; Chapter 15:Unit 15.18.

32. Glaab T, Daser A, Braun A, Neuhaus-Steinmetz U, Fabel H, Alarie Y, Renz H. Tidal midexpiratory flow as a measure of airway hyperresponsiveness in allergic mice. Am J Physiol Lung Cell Mol Physiol. 
2001;280:L565-L573.

33. Duan W, Chan JH, Wong CH, Leung BP, Wong WS. Anti-inflammatory effects of mitogen-activated protein kinase kinase inhibitor U0126 in an asthma mouse model. J Immunol. 2004;172:7053-7059.

34. Tabatabaian F, Ledford DK. Omalizumab for severe asthma: toward personalized treatment based on biomarker profile and clinical history. J Asthma Allergy. 2018;11:53-61.

35. Holgate ST, Wenzel S, Postma DS, Weiss ST, Renz H, Sly PD. Asthma. Nat Rev Dis Primers. 2015;1:15025.

36. Lambrecht BN, Hammad H. The immunology of asthma. Nat Immunol. 2015;16:45-56.

37. Tritar-Cherif F, Ben M'Rad S, Merai S, Djenayah F. Corticotherapy for asthma in the child. Tunis Med. 2002;80:1-6. French.

38. Southworth T, Mason S, Bell A, Ramis I, Calbet M, Domenech A, Prats N, Miralpeix M, Singh D. PI3K, p38 and JAK/STAT signalling in bronchial tissue from patients with asthma following allergen challenge. Biomark Res. 2018;6:14.

39. Kleiman A, Tuckermann JP. Glucocorticoid receptor action in beneficial and side effects of steroid therapy: lessons from conditional knockout mice. Mol Cell Endocrinol. 2007;275:98-108.

40. Hocaoglu AB, Karaman O, Erge DO, Erbil G, Yilmaz O, Bagriyanik A, Uzuner N. Glycyrrhizin and long-term histopathologic changes in a murine model of asthma. Curr Ther Res Clin Exp. 2011;72:250261.

41. Oh SW, Cha JY, Jung JE, Chang BC, Kwon HJ, Lee BR, Kim DY. Curcumin attenuates allergic airway inflammation and hyper-responsiveness in mice through NF- $\mathrm{BB}$ inhibition. J Ethnopharmacol. 2011;136:414-421.

42. Zhang W, Zhang X, Sheng A, Weng C, Zhu T, Zhao W, Li C. $\gamma$-Secretase inhibitor alleviates acute airway inflammation of allergic asthma in mice by downregulating Th17 cell differentiation. Mediators Inflamm. 2015;2015:258168.

43. Deshmukh R, Kaundal M, Bansal V, Samardeep. Caffeic acid attenuates oxidative stress, learning and memory deficit in intracerebroventricular streptozotocin induced experimental dementia in rats. Biomed Pharmacother. 2016;81:56-62.

44. Wenzel SE. Asthma: defining of the persistent adult phenotypes. Lancet. 2006;368:804-813.

45. Turner DJ, Mulholland MW. Calcium signaling pathways in the enteric nervous system. Int J Surg Investig. 1999;1:87-97.

46. Elsner J, Kapp A. Regulation and modulation of eosinophil effector functions. Allergy. 1999;54:15-26.

47. Wei M, Chu X, Guan M, Yang X, Xie X, Liu F, Chen C, Deng X. Protocatechuic acid suppresses ovalbumin-induced airway inflammation in a mouse allergic asthma model. Int Immunopharmacol. 2013;15:780-788.

48. Lee MY, Seo CS, Lee JA, Lee NH, Kim JH, Ha H, Zheng MS, Son JK, Shin HK. Anti-asthmatic effects of Angelica dahurica against ovalbumin-induced airway inflammation via upregulation of heme oxygenase-1. Food Chem Toxicol. 2011;49:829-837.

49. Busse WW, Lemanske RF Jr. Asthma. N Engl J Med. 2001;344:350362.

50. Busse WW, Coffman RL, Gelfand EW, Kay AB, Rosenwasser LJ. Mechanisms of persistent airway inflammation in asthma. A role for T cells and T-cell products. Am J Respir Crit Care Med. 1995;152:388-393.

51. Cohn L, Tepper JS, Bottomly K. IL-4-independent induction of airway hyperresponsiveness by Th2, but not Th1, cells. J Immunol. 1998;161:3813-3816.

52. Bisset LR, Schmid-Grendelmeier P. Chemokines and their receptors in the pathogenesis of allergic asthma: progress and perspective. Curr Opin Pulm Med. 2005;11:35-42.

53. Ngoc PL, Gold DR, Tzianabos AO, Weiss ST, Celedón JC. Cytokines, allergy, and asthma. Curr Opin Allergy Clin Immunol. 2005;5:161166.

54. Desai D, Brightling C. Cytokines and cytokine-specific therapy in asthma. Adv Clin Chem. 2012;57:57-97.

55. Fish SC, Donaldson DD, Goldman SJ, Williams CM, Kasaian MT. $\operatorname{IgE}$ generation and mast cell effector function in mice deficient in IL-4 and IL-13. J Immunol. 2005;174:7716-7724.

56. Kolls JK, Lindén A. Interleukin-17 family members and inflammation. Immunity. 2004;21:467-476.

57. Wakashin H, Hirose K, Maezawa Y, Kagami S, Suto A, Watanabe N, Saito Y, Hatano M, Tokuhisa T, Iwakura Y, Puccetti P, Iwamoto I, Nakajima H. IL-23 and Th17 cells enhance Th2-cell-mediated eosinophilic airway inflammation in mice. Am J Respir Crit Care Med. 2008;178:1023-1032.

58. Li J, Zhang B. Apigenin protects ovalbumin-induced asthma through the regulation of Th17 cells. Fitoterapia. 2013;91:298-304.

59. Sun YC, Zhou QT, Yao WZ. Sputum interleukin-17 is increased and associated with airway neutrophilia in patients with severe asthma. Chin Med J (Engl). 2005;118:953-956.

60. Wilson RH, Whitehead GS, Nakano H, Free ME, Kolls JK, Cook DN. Allergic sensitization through the airway primes Th17-dependent neutrophilia and airway hyperresponsiveness. Am J Respir Crit Care Med. 2009;180:720-730.

61. Ma C, Ma Z, Fu Q, Ma S. Curcumin attenuates allergic airway inflammation by regulation of CD4+CD25+ regulatory T cells (Tregs)/ Th17 balance in ovalbumin-sensitized mice. Fitoterapia. 2013;87:5764.

62. Ji X, Han M, Yun Y, Li G, Sang N. Acute nitrogen dioxide (NO2) exposure enhances airway inflammation via modulating Th1/Th2 differentiation and activating JAK-STAT pathway. Chemosphere. 2015;120:722-728.

63. Mao X, Ren Z, Parker GN, Sondermann H, Pastorello MA, Wang W, McMurray JS, Demeler B, Darnell JE Jr, Chen X. Structural bases of unphosphorylated STAT1 association and receptor binding. Mol Cell. 2005;17:761-771.

64. O’Shea JJ, Kontzias A, Yamaoka K, Tanaka Y, Laurence A. Janus kinase inhibitors in autoimmune diseases. Ann Rheum Dis. 2013;72 Suppl 2:ii111-115.

65. O'Shea JJ, Holland SM, Staudt LM. JAKs and STATs in immunity, immunodeficiency, and cancer. NEngl J Med. 2013;368:161-170.

66. Zhong Z, Wen Z, Darnell JE Jr. Stat3: a STAT family member activated by tyrosine phosphorylation in response to epidermal growth factor and interleukin-6. Science. 1994;264:95-98.

67. Abroun S, Saki N, Ahmadvand M, Asghari F, Salari F, Rahim F. STATs: an old story, yet mesmerizing. Cell J. 2015;17:395-411.

68. Walford HH, Doherty TA. STAT6 and lung inflammation. JAKSTAT. 2013;2:e25301.

69. Dallman MJ, Smith E, Benson RA, Lamb JR. Notch: control of lymphocyte differentiation in the periphery. Curr Opin Immunol. 2005;17:259-266.

70. Osborne BA, Minter LM. Notch signalling during peripheral T-cell 
activation and differentiation. Nat Rev Immunol. 2007;7:64-75.

71. Laky K, Fowlkes BJ. Notch signaling in CD4 and CD8 T cell development. Curr Opin Immunol. 2008;20:197-202.
72. Zhang W, Nie Y, Chong L, Cai X, Zhang H, Lin B, Liang Y, Li C. PI3K and Notch signal pathways coordinately regulate the activation and proliferation of T lymphocytes in asthma. Life Sci. 2013;92:890-895. 